\title{
Barkhausen Noise Stress Characteristic of P265GH Boiler Steel
}

\begin{abstract}
T. GarstKA*
Czestochowa University of Technology, Faculty of Materials Processing Technology and Applied Physics al. Armii Krajowej 19, 42-200 Częstochowa

In this paper characterization of internal mechanical stress state in boiler steel plate by the Barkhausen effect based method was presented. The affecting of calibration functions shape by tensile and compressive residual stress was observed. Beside of the significant residual stress anisotropy in sub-surface layers, unfavorable location of main directions of stress was revealed on both sides of the plate. The new method of calibration function without heat treatment of calibration specimens was elaborated and presented also. The investigations of Barkhausen noise as function of applied stress for different intensity and frequency of magnetization current were performed. Based on this, optimal magnetization conditions of doing measurement were estimated. Own construction of measuring apparatus for experiments was used.
\end{abstract}

PACS: 75.60.Ej

\section{Introduction}

Majority of all manufacturing processes of production steel sheets and plates introduces internal, so-called, residual stress. Generally, constituted stress state at the stages, e.g. cooling or straightening, is negatively influencing on utility properties.

Such stress state occurs during cutting and forming elements, when the accumulated residual stress releasing is causing their deformation. These problems were observed in P265GH steel plate used for boiler installation. Long pieces cut from this sheet were spontaneously twisted (Fig. 1).

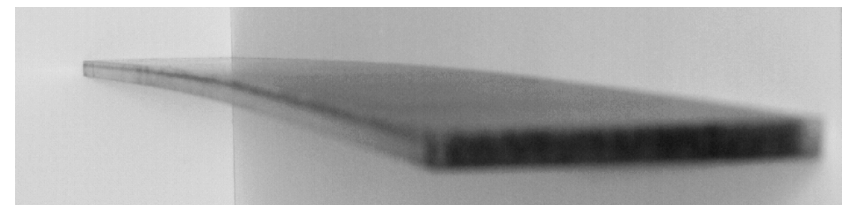

Fig. 1. Deformation of strip element cut off from investigated plate.

During searching of the causes of deformation, the diagnostic examinations were performed [1]. But the micro hardness and microstructure testing did not reveal significant differences in mechanical properties that could be the reason of it. Only preliminary investigations by nondestructive method, Barkhausen effect based, pointed out on existence of unfavorable residual stress state in the plate.

This method relies on measurement by special equipment, series of electrical pulses - magnetic Barkhausen

* e-mail: tomasz.garstka@wip.pcz.pl noise (MBN), induced in search coil by discontinuous movement of domains' walls (Barkhausen jumps) during magnetization of tested ferromagnetic materials [2]. It is observed and well-known as characteristic steps on the hysteresis loop. Course of the Barkhausen phenomenon, as well as electrical and geometrical parameters of the MBN, depends on microstructure (type, disclocations, defects, etc), stress state and magnetization state of tested material. This effect is utilized for nondestructive comparative investigations of ferromagnetic materials, especially stress state in steels $[3,4]$.

These cursory MBN examinations of P265GH steel plate have given no answer about real values of the stress. Due to this, it was necessary to conduct more detailed Barkhausen research, covering determination of calibration functions and magnetization conditions.

\section{Material characteristic and sample preparation}

The investigated steel plate is used for hot water installation elements. As in delivery state, sheet dimension are $5 \mathrm{~mm} \times 1500 \mathrm{~mm} \times 5000 \mathrm{~mm}$. For the investigations, a small piece with dimensions $110 \mathrm{~mm} \times 400 \mathrm{~mm}$ was cut out.

This steel has typical ferritic-pearlitic microstructure. Most interesting from the point of view of doing Barkhausen measurements, average grain size in both subsurface layers of sheet were similar but some differences existed in classes' distributions of grain size.

The two samples for calibration were cut off with dimension $110 \mathrm{~mm} \times 20 \mathrm{~mm}$. The directions of cutting were perpendicular to each other as is shown in Fig. 2. The thickness of the samples was $5 \mathrm{~mm}$, the same as the sheet in delivery state.

In order to keep natural conditions of contact of plate with the measuring head, no surface treatment (such as 


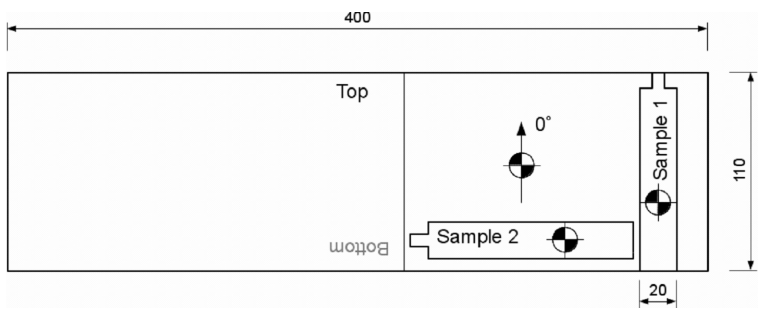

Fig. 2. Orientation of calibration samples placement with marked measurement points.

polishing or other) was applied to samples. In this way, it lets to carry out the experiment as in industrial environments, although it increases possibilities of occurring errors and uncertainty. The one of surfaces of plate was marked and assumed as the "top", second - as the "bottom". The arrangement of measurement points (on both sides) and orientation of reference direction $0^{\circ}$ is presented in Fig. 2.

\section{Experiment set-up and parameters}

The investigations were conducted using the measuring apparatus, developed at Częstochowa University of Technology, at Faculty of Materials Processing Technology and Applied Physics [4]. It consists of three main parts: magnetiziation module, amplifiers blocking and processing unit. The detailed presentation of it construction is shown in Fig. 3 .

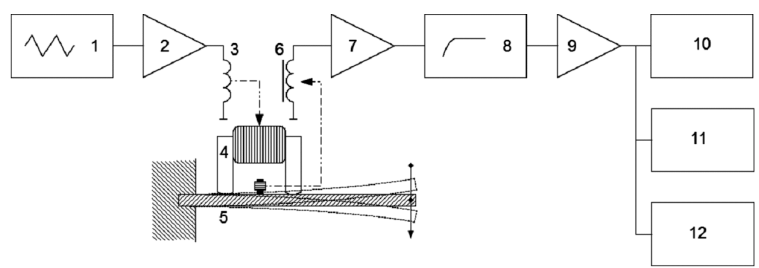

Fig. 3. Block diagram of measuring set-up: $1-$ sawtooth generator, 2 - power amplifier, 3 - magnetization coil, 4 - yoke, 5 - tested material, 6 - detection coil, 7 - preamplifier, 8 - high band filter, 9 - amplifier, 10 - RMS converter, 11 - envelope detector, 12 - Barkhausen pulse former.

The magnetization frequency may be chosen from six values between $1 \mathrm{~Hz}$ and $38 \mathrm{~Hz}$ and the output current can reach up to $1 \mathrm{~A}$, depending on construction of measuring head magnetizing coil.

In the measuring part, the high pass filter had cut-off frequency at $1 \mathrm{kHz}$. Total gain of both amplifiers was $120 \mathrm{~dB}$ and can be changed with $5 \mathrm{~dB}$ steps.

The processing unit let to determine parameters of MBN as the Root Mean Square value, envelope signal or TTL pulse according to Barkhausen jumps over the given voltage level. For further computer data processing, DAQ 3000 board, $1 \mathrm{MHz}$, was used.
The integral parts of apparatus are measuring heads for inducing and detecting Barkhausen noise. The measuring head could not be too small due to nonhomogeneity of materials and surface state profile influencing on magnetization and detection coil contact. From the other hand, if general dimensions are relative big, the influence of edge impact is significant and must be compensated.

In this experiment, the width of measuring head yoke was a few many times smaller than width of samples to avoid impact of edges. To keep stable magnetization during calibration, when the sample is bent, the yoke poles were rounded. The average length of the magnetic flux path through the $\mathrm{C}$ - shape yoke and tested material was $60 \mathrm{~mm}$. The magnetization winding has 150 turns of $0.5 \mathrm{~mm}$ diameter. As the detection coil, the commercial SMD coil, with ferrite core was used. Its measurement area was $10 \mathrm{~mm}^{2}$.

The external stress was applied by the special equipment. One side of the strip shaped specimen was fixed and the second was controlled bent by multi screw to introduce the stress state. The stress value in point of the detection coil placement was calculated from classical equations of mechanic for bending beam.

The compressive and tensile stresses were applied to each sample with $40 \mathrm{MPa}$ step. The following load cycles were applied: $0 \rightarrow \sigma_{\max }^{+} \rightarrow 0 \rightarrow \sigma_{\text {max }}^{-} \rightarrow 0$, and the average values of measured parameters (RMS and amplitude) were calculated.

The experiments were performed for different magnetization conditions. The shape of magnetizing current was triangle. The three frequencies $f_{m}$ were used: $6 \mathrm{~Hz}$, $12 \mathrm{~Hz}, 22 \mathrm{~Hz}$. Also the five magnetization values of currents $I_{m}$ were used: $100 \mathrm{~mA}, 200 \mathrm{~mA}, 300 \mathrm{~mA}, 400 \mathrm{~mA}$ and $500 \mathrm{~mA}$. During the initial tests, current $100 \mathrm{~mA}$ was used, but for $6 \mathrm{~Hz}$, the Barkhausen noise has very low amplitude and these series of measurement were canceled and not taken into consideration. Also, the highest value of the magnetizing current, $500 \mathrm{~mA}$ was used only for optimization of usable range of magnetization conditions and full range of calibration was not performed.

To cover different MBN levels at wide range of magnetization's parameters changes, the $110 \mathrm{~dB}$ total gain of both amplifiers was set.

Based on the previous works of author [5, 6] average uncertainty of RMS measurements covering nonrepeatability of application the measuring head to the samples, non-homogeneity of steel structure and others errors, must be estimated up to $10 \%$.

\section{Results}

Before the main tests, at the state of no external stress loads, the oscillograms of Barkhausen noise in calibration specimens were recorded. They were presented in Fig. 4. The magnetization current intensity $I_{m}$ was $300 \mathrm{~mA}$ and the frequency $f_{m}$ was $12 \mathrm{~Hz}$. For other magnetization frequencies, the shapes of the oscillograms were similar. 


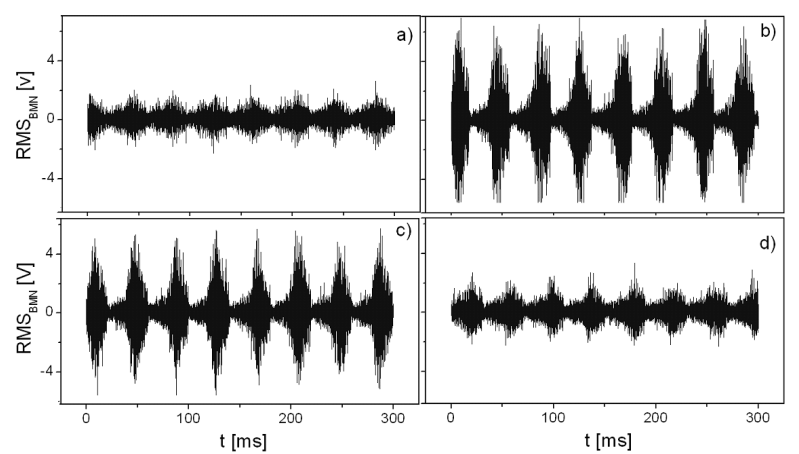

Fig. 4. Oscillograms of Barkhausen noise at non external stress loads: a) sample 1, side A - top; b) sample 2, side B - bottom; c) - sample 2, side A - top; sample 2, side $\mathrm{B}$ - bottom.

As can be observed, on the both sides, the main direction of Barkhausen noise intensity was different.

In next stage of study, $R M S_{\mathrm{MBN}}$ and amplitude of MBN were measured as a function of the external stress state applied to the samples. The most representative results of dependences $R M S_{\mathrm{MBN}}=f(\sigma)$ for three magnetization currents at $12 \mathrm{~Hz}$ are shown in Fig. 5. For other frequencies $6 \mathrm{~Hz}$ and $22 \mathrm{~Hz}$ these dependences have the same character. In addition, the dependences of MBN amplitude in function of applied stress had similar courses (Fig. 6).

Analyzing course of the obtained families of the curves $R M S_{\mathrm{MBN}}=\left.f(\sigma)\right|_{\text {Im=var }}$ (Fig. 5), significant differentiation of their shapes in the specimens cut out for perpendicular directions may be observed. Such state existed on both sides of sheet. Moreover, they were not similar to known sigmoidal curves of calibration functions and rather seem to be like "halves" of them. This situation can be explained only if the residual stress are added to external stress load.

In this form, these curves were not usable for universal stress determination and free direction of magnetization angle. Taking into consideration significant values of residual stress, over $100 \mathrm{MPa}$, the annealing in high temperature must be applied to stress state removal.

Author in [8] analyzed the problem of stress relaxation in calibration samples by the heat treatment in Barkhausen noise measurements. According to this, low temperature and short time annealing does not ensure to achieve the state without stress in the specimen. On the other hand, long time and high temperature on annealing, although being able to provide full stress state relaxation, will be modifying the microstructure.

In present work, new method was elaborated to obtain universal calibration function without heat treatment of calibration samples. An idea of it relies on "gluing" the calibration functions received for two perpendicular directions into one, and balancing to fix zero point $(0 \mathrm{MPa})$ in the middle of linear part of characteristic (Fig. 7). In this place, the most of dependences of MBN intensity in

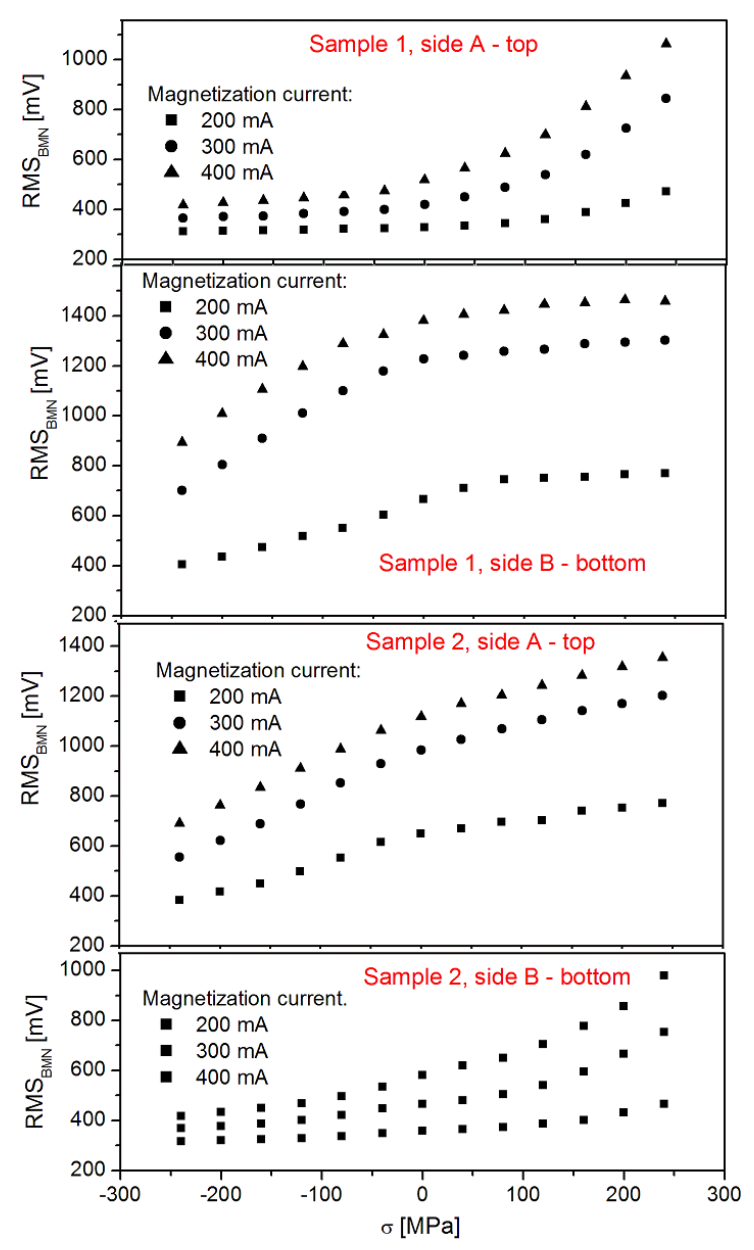

Fig. 5. Families of $R M S_{\mathrm{MBN}}$ in function of applied external stress in samples.

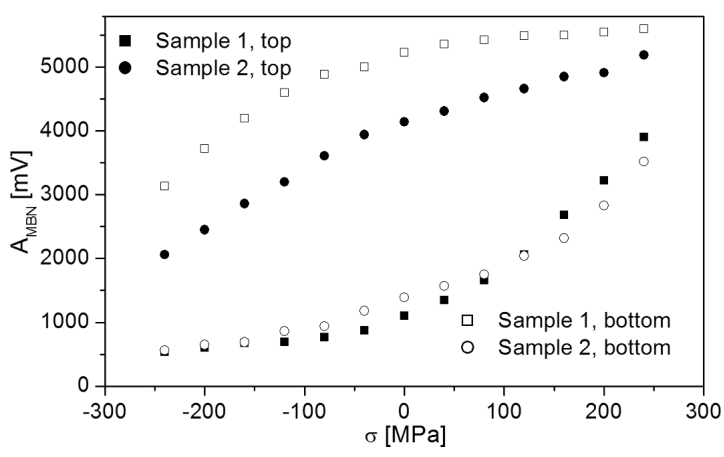

Fig. 6. Dependences of MBN amplitude in function of applied stress at $12 \mathrm{~Hz}, 400 \mathrm{~mA}$.

function of stress, have equilibrium at the middle of linear part of characteristic or between of saturation parts. In next step, the new characteristic should be limited below stresses causing plastic deformation.

The examples of calibration functions designated in this manner for $f_{m}=22 \mathrm{~Hz}$ and $I_{m}=200 \mathrm{~mA}$ is shown in Fig. 8. The different course for tensile stress can be prob- 


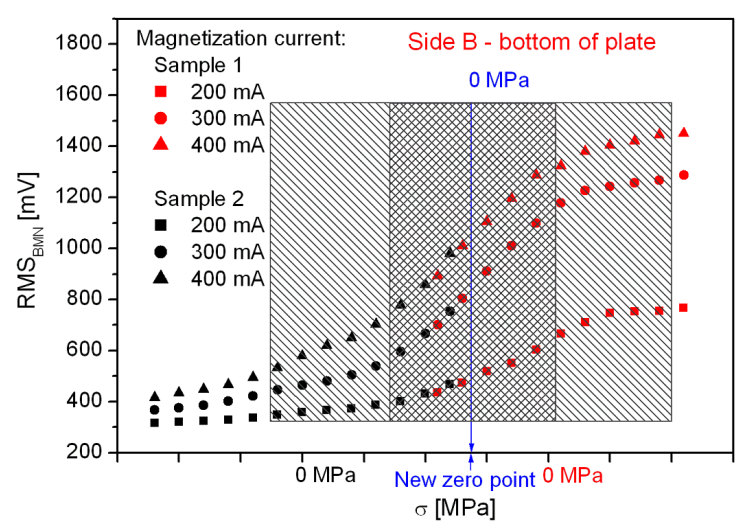

Fig. 7. Explanation of new calibration function creation procedure.

ably caused by the noticed differentiation in microstructure of both surface layers - distribution of ferrite grain's size classes.

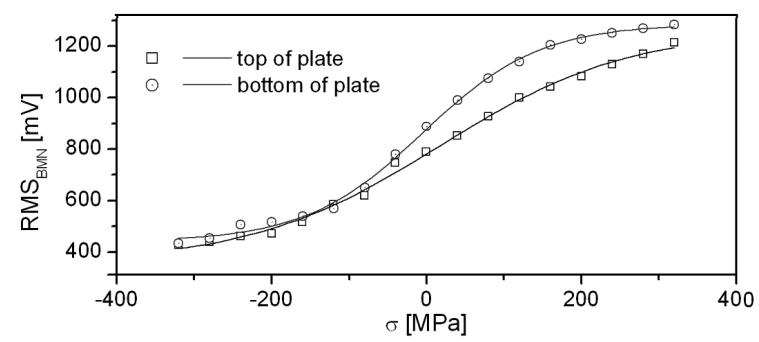

Fig. 8. Calibration functions at $f_{m}=22 \mathrm{~Hz}$ and $I_{m}=$ $200 \mathrm{~mA}$.

Estimated residual stress values on this calibration characteristic base, in function of magnetization direction angle, in Fig. 9 were presented. The measurement point was placed as shown in Fig. 2. The MBN measurement with angular step of $22.5^{\circ}$ were done on the both side of the investigated steel sheet. The maximal measured residual stresses reach significant high values. On the top side of the plate, the $-150 \mathrm{MPa}$ compressive stress was observed, whereas on the opposite side the tensile stress was near of $+150 \mathrm{MPa}$.

\section{Magnetization conditions}

Advanced method of residual stress measurements by BN method, covering e.g. determination of stress in function of depth, need to be performed for different magnetization frequency. Also, simple stress measurements ought to be done for magnetization conditions, when the MBN is most sensitive to residual stress changes.

On the base of received results during stress evaluation, the optimal conditions of magnetizing for used experiment set-up were estimated. For this purpose, the developed Eq. (1) for characterization of dynamic of MBN changes in function of stress was used [8].

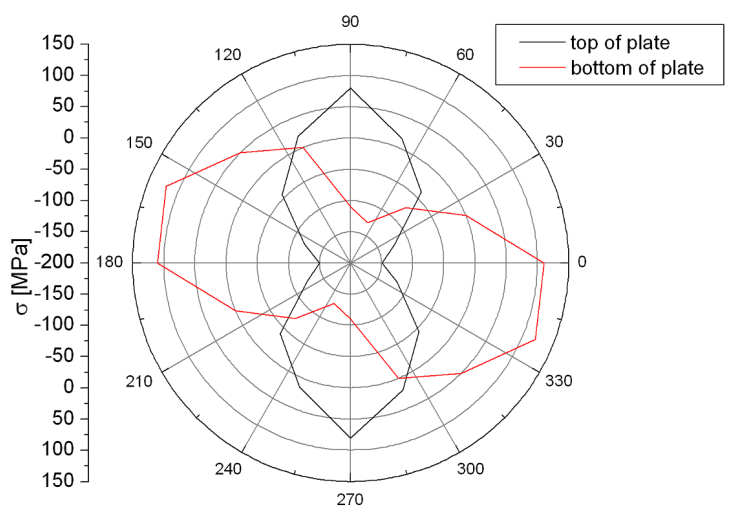

Fig. 9. Radial diagram of residual stress distribution.

$$
\Delta R M S_{\mathrm{MSB}}=\frac{R M S_{\mathrm{MBN}}\left(\sigma^{+}\right)-R M S_{\mathrm{MBN}}\left(\sigma^{-}\right)}{R M S_{\mathrm{MBN}}\left(\sigma^{+}\right)},
$$

where $\triangle R M S_{\mathrm{MBN}}-$ indicator of dynamics, $R M S_{\mathrm{MBN}}\left(\sigma^{+}\right)$- $R M S$ value of $\mathrm{MBN}$ for maximum tensile applied stress, $R M S_{\mathrm{MBN}}\left(\sigma^{-}\right)-R M S$ value of MBN for maximum compressive applied stress

Taking into consideration anisotropy of stress state in the tested sheet for calculation index Eq. (1), the values of RMS were taken not for one sample but for both, after the joining operation described above.

The map of this indicator as a function of magnetization current parameters in Fig. 10 was shown. Based on practical author's experience, the acceptable value of this indicator should be at least greater than 0,5 to obtain satisfactory resolution of the stress measurement. As can be observed, for all frequencies, magnetization current must be over $200 \mathrm{~mA}$ and generally, the best conditions exists for $I_{m}$ between $300 \mathrm{~mA}$ and $400 \mathrm{~mA}$.

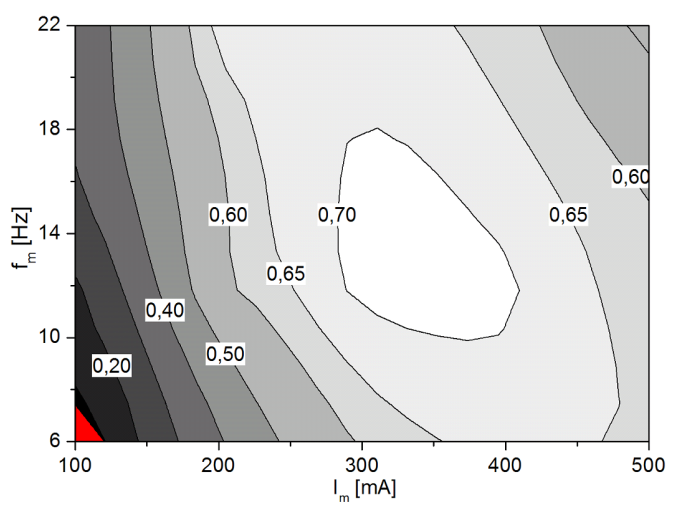

Fig. 10. Influence of magnetization conditions - frequency and current intensity on value of $\triangle \mathrm{RMS}_{M B N}$ indicator.

\section{Summary}

The study to assess the level of residual stresses was presented in this paper and it revealed a high value of 
these stresses in tested plate. As an effect of it, the calibration curves were affected by this initial stress state, what could be observed as their characteristic shift. The proposed procedure of calibration characteristics reconstruction includes gluing and positioning of the calibration curves and seems to be the best solution when the low temperature heat treatment does not provide fully stress relaxation in calibration samples. To compare results the next stages of this study will be covering heat treatment influence on stress relaxation level and Barkhausen noise modification in this kind of steel sheets.

\section{References}

[1] T. Garstka, B. Koczurkiewicz, G. Golański, Advances in Material Science, 10, 81, (2010).

[2] G. Durin, S. Zapperi, The Microscopical Origin of Barkhausen Noise: A Review of Recent Results, Materials of 4-th International Conference on Barkhausen Noise and Micromagnetic Testing, Brescia, (2003).
[3] J. Gauthier, T. Krause, D. Atherton, NDTEE International, 31, 23, (1998).

[4] T. Garstka, Pomiary Automatyka Robotyka, 6, 58, (2008).

[5] T. Garstka, Proceedings of VII Conference Systemy Pomiarowe w badaniach naukowych i przemyśle, Łagów, 55, (2010).

[6] T. Garstka, Electrical Review 86, 62, (2010).

[7] T. Garstka, Proceedings of 10th International Science Conference Nowe technologie $i$ osiagnięcia $w$ metalurgii $i$ inżynierii materiałowej Częstochowa, 93, (2009).

[8] T. Garstka, Solid State Phenomena, 165, 50, (2010). 